\title{
The National Emergency Access Target (NEAT): can quality go with timeliness?
}

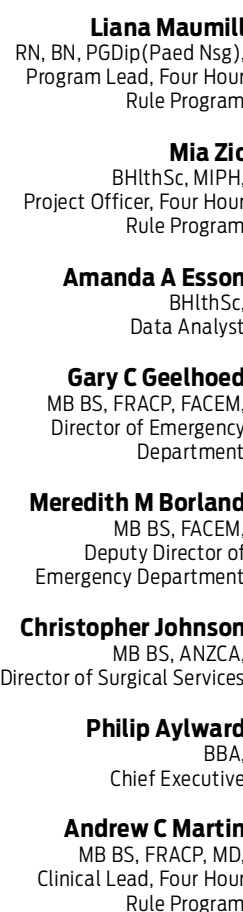

Princess Margaret Hospital for Children, Perth, WA.

andrew.martin@ health.wa.gov.au

MJA 2013; 198: 153-157 doi: 10.5694/mjal2.11063 ncreasing demand on health services during times of austerity has necessitated examination of the way we deliver health care. ${ }^{1,2}$ In 2008, Western Australian tertiary hospital emergency departments (EDs) were experiencing the highest rates of access block (the percentage of patients who wait longer than 8 hours for an inpatient bed) in the country., The well documented relationship between access block and poor health outcomes for patients, ${ }^{5-9}$ coupled with adverse media and public opinion about Western Australia's public hospitals, demanded a significant response. A Minister for Health delegation travelled to the United Kingdom to examine National Health Service (NHS) reforms, ${ }^{10,11}$ to learn from their successes to improve health care delivery in WA. Subsequently, in April 2009, the Four Hour Rule (FHR) Program was launched in WA. ${ }^{12}$ Stage 1 of the program involved the state's four tertiary public hospitals: Princess Margaret Hospital for Children, Royal Perth Hospital, Sir Charles Gairdner Hospital and Fremantle Hospital.

WA hospitals were initially set the same final FHR target as hospitals in the UK, which was that $98 \%$ of all patients presenting to their ED should be admitted, discharged or transferred within 4 hours of arrival. However, key differences between the two programs were that the WA FHR program had a clear and defined focus on monitoring patient safety and quality outcomes, that there were no financial incentives or sanctions for hospitals that achieved or failed to achieve the set targets, and the launch coincided with a challenging time in global finances. This presented a compelling need to examine systems and processes, so, while limited funding was made available to support change initiatives, it was agreed there would be no allocation of recurrent funding, meaning no additional beds or staff. In June 2010, the UK government introduced a suite of new clinical quality indicators and reduced their

\section{Abstrac}

Objective: To report the experience of implementing a 4-hour-rule program. Design, setting and participants: A 3-year whole-of-hospital clinical service redesign program in a tertiary paediatric hospital in Western Australia, involving all patients presenting to the emergency department (ED) from 1 January 2009 to 31 December 2011.

Main outcome measures: Percentage of patients admitted, discharged or transferred from the ED within 4 hours of arrival at triage, and percentage of patients discharged from inpatient wards before $10 \mathrm{am}$.

Results: The percentage of patients admitted, discharged or transferred within 4 hours of arrival at the ED increased from $87 \%$ in 2009 to $95 \%$ in 2011 . Safety and quality measures, including the admission rate from the ED, unplanned reattendances at the ED within 48 hours of discharge, patient complaints and inhospital mortality, remained unchanged. The percentage of patients discharged from inpatient wards before 10 am increased from $18 \%$ in 2009 to $30 \%$ in 2011 .

Conclusions: The introduction of a 4-hour-rule program has resulted in improved timeliness of care for patients throughout the hospital, both in the ED and inpatient wards, with no adverse impact on the quality and safety of clinical care.

FHR target to $95 \% .^{13}$ The purpose of these new indicators, which were very similar to those already being monitored in WA's FHR program, was to broaden the measurement of quality to cover effectiveness of treatment and patient satisfaction.

The aim of WA's FHR program was to improve patients' experience and quality of care by reducing delays in the ED and streamlining processes throughout the hospital. With the recent introduction of the National Emergency Access Target (NEAT), ${ }^{14}$ we report our experience of establishing a successful FHR program.

\section{Methods}

Princess Margaret Hospital for Children $(\mathrm{PMH})$ in Perth, WA, is a 220 bed tertiary paediatric hospital, that has more than 65000 presentations to the ED annually. The FHR program used a clinical services redesign model, based on principles from Six Sigma and "lean thinking". Clinical services redesign is a proven, rigorous international model used in large complex organisations. ${ }^{15-17}$ The model is data-driven and consumer(ie, patient-) focused. Six Sigma is a disciplined, data-driven approach for eliminating defects in processes. ${ }^{18}$ The
Six Sigma improvement model consists of five phases: Define, Measure, Analyse, Improve and Control (DMAIC). Lean is a collection of tools and principles that aim to improve health services by eliminating waste, adding value to processes and allowing continuous improvement. ${ }^{19}$

The FHR program commenced in April 2009 with a strictly time-limited 6-month diagnostic phase, followed by the implementation of solutions over 18 months. While the FHR program office led the DMAIC process, each step, including all solutions, were determined, developed and implemented by hospital staff. The program targets were for $85 \%$ of patients attending the ED to be admitted, discharged or transferred within 4 hours of arrival by April 2010, $95 \%$ by October 2010 and $98 \%$ by April 2011.

\section{DMAIC methods}

Define phase (5 weeks): The "patient journey" was critically examined and mapped from arrival at triage to discharge from hospital. Open forums were attended by more than 300 hospital staff; their purpose was to map current processes and identify key issues (the "voice of the organisation"). We also collected 
1 Quality measures for the Four Hour Rule Program at Princess Margaret Hospital, Perth, Western Australia, 2009 to 2011

\begin{tabular}{|c|c|c|c|}
\hline Measure & 2009 & 2010 & 2011 \\
\hline Emergency department (ED) attendances & 60060 & 65818 & 67473 \\
\hline Admissions from ED & 11174 & 11372 & 11505 \\
\hline Rate of admissions from ED $(95 \% \mathrm{Cl})$ & $18.60 \%(18.29 \%-18.92 \%)$ & $17.28 \%(16.99 \%-17.57 \%)$ & $17.05 \%(16.77 \%-17.34 \%)$ \\
\hline Unplanned reattendances within 48 hours & 352 & 339 & 428 \\
\hline Rate of unplanned reattendances ( $95 \% \mathrm{Cl}$ ) & $0.59 \%(0.53 \%-0.65 \%)$ & $0.52 \%(0.46 \%-0.57 \%)$ & $0.63 \%(0.58 \%-0.70 \%)$ \\
\hline Patient complaints & 21 & 29 & 30 \\
\hline Rate of patient complaints $(95 \% \mathrm{Cl})$ & $0.03 \%(0.02 \%-0.05 \%)$ & $0.04 \%(0.03 \%-0.06 \%)$ & $0.04 \%(0.03 \%-0.06 \%)$ \\
\hline Inhospital mortality for admissions from ED & 9 & 16 & 10 \\
\hline $\begin{array}{l}\text { Rate of inhospital mortality for } \\
\text { admissions from ED }(95 \% \mathrm{Cl})\end{array}$ & $0.08 \%(0.04 \%-0.15 \%)$ & $0.14 \%(0.08 \%-0.22 \%)$ & $0.09 \%(0.04 \%-0.16 \%)$ \\
\hline
\end{tabular}

information from children, adolescents and families about their experiences (the "voice of the patient").

Measure phase (6 weeks): After the collection of baseline data, we developed a data measurement plan, including key high-level and lowlevel measures relating to the patient journey.

Analyse phase (6 weeks): We determined root causes of all major issues, generated, and then tested hypotheses using data and statistical analyses, to validate or refute each root cause.

Improve phase (7 weeks): Hospital staff determined solutions to the root cause of each issue. Implementation plans and business cases were developed, presented to the hospital Executive and submitted to the Department of Health (DoH) to be considered for funding.

Control phase (18 months): Solutions were implemented, with an eventual shift in focus from change management to expected performance, and integration of solutions into normal hospital business.

\section{Personnel}

An FHR program office was established, employing one full-time equivalent (FTE) Program Lead (senior registered nurse), a 0.2 FTE Clinical Lead (paediatrician), and one FTE Project Officer. A data analyst and program adviser were seconded from the DoH during the first 6 months of the program. Members of the program office and key senior staff received training in clinical services redesign methods. Clinical staff from areas of the hospital that would be making changes were identified and invited to join solution groups. Each solution group appointed a chairperson, who was responsible for leading the change and was assigned a member of the hospital Executive, who was accountable for implementing the change.

\section{Governance}

Strong governance was required to provide clarity and direction around roles, responsibilities and the authority to implement solutions. The FHR program governance structure considered and clearly articulated how the FHR program aligned with PMH's current and future organisational structure, as well as with the structure of WA Health.

\section{Outcome measures and data analysis}

Key outcome measures included the overall FHR percentage (ie, percentage of all patients presenting to the ED whose management complied with the FHR), and the percentages of patients admitted, discharged or transferred from the ED for whom this happened within 4 hours of arrival at triage, and the percentage of patients discharged from inpatient wards before $10 \mathrm{am}$ and $12 \mathrm{pm}$. Critical countermeasures (Box 1 ) were also reported to ensure that any potential adverse effects of the program were apparent immediately. The Princess Margaret Hospital Ethics Committee approved the reporting of this study (ethics number, 3637).

\section{Results}

The overall FHR performance at PMH increased steadily over the first 3 years of the program, averaging $87 \%$ in 2009 and 95\% in 2011 (Box 2). The increase in overall performance resulted from improvements in both the percentage of patients being admitted to hospital within 4 hours (62\% in 2009; $74 \%$ in 2010; and $80 \%$ in 2011), and those being discharged home from the ED within 4 hours (94\% in 2009; $96 \%$ in 2010; and $98 \%$ in 2011).

The Define phase of DMAIC identified more than 400 issues, with common themes including duplication of processes, lack of resources, mismatch between demand and availability of key services, poor communication and inadequate discharge planning. After grouping, 30 major issues remained. These were measured to determine their size and impact, followed by root-cause analysis and generation of solutions (Box 3).

ED attendances increased by $12.3 \%$ from 2009 to 2011 (Box 1). During this period, the admission rate from the ED fell, but with the increase in ED attendances, the total number of patients admitted increased marginally. There was no significant change in the percentage of unplanned reattendances to the $\mathrm{ED}$ within 48 hours of discharge, the percentage of patient complaints or inhospital mortality. In addition, the number of elective surgeries performed at $\mathrm{PMH}$ increased by $9 \%$ from 2009 to 2011 .

The mean time from patients arriving at triage to being seen by an ED doctor did not change (44 minutes in 2009; 47 minutes in 2010; and 46 minutes in 2011). There was a reduction in the time from being seen by a doctor to the decision to admit being made (96 minutes in 2009; 84 minutes in 2010; and 79 minutes in 2011) and in the time from the decision to admit to the patient departing the ED (109 
2 Overall Four Hour Rule Program performance at Princess Margaret Hospital, Perth, Western Australia, 2009 to 2011

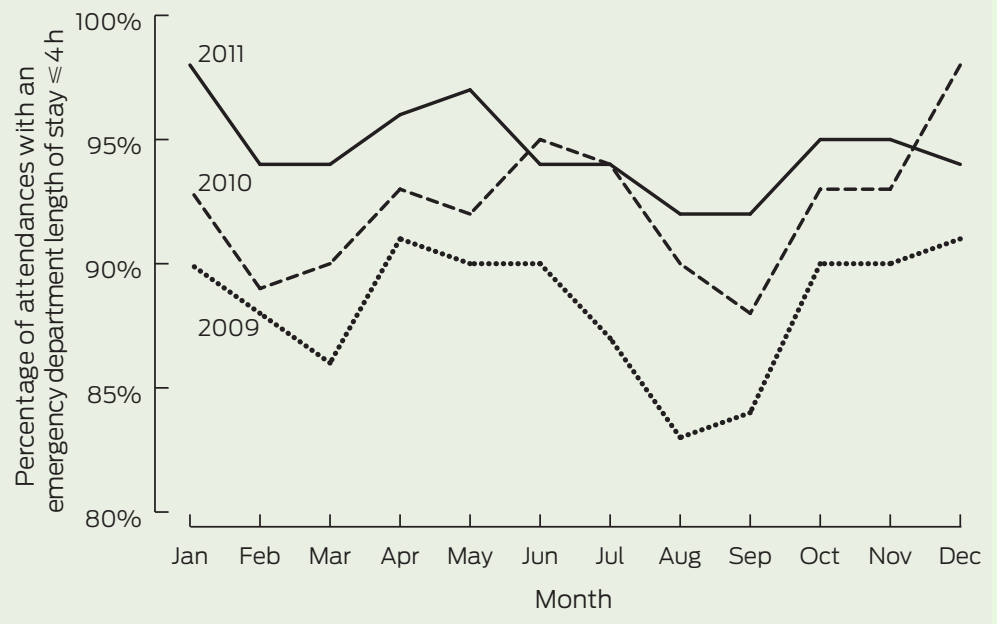

minutes in 2009; 66 minutes in 2010; and 46 minutes in 2011).

In response to UK studies suggesting that some patients were being "pushed" out of EDs just before the 4hour target, with a spike in ED departures between 3.5 hours and 4 hours, ${ }^{20-22}$ we used a critical countermeasure, with a weekly figure show- within 4 hours of arrival. Access block fell from $2.4 \%$ in 2009 to $0.6 \%$ in 2011.

The key factor contributing to the improvement in patients being admitted from the ED within 4 hours was the increase in the percentage of patients being discharged home from an inpatient bed before $10 \mathrm{am}$. In April 2009 , only $18 \%$ of all patients discharged home on a particular day were discharged before $10 \mathrm{am}$, with $50 \%$ still occupying their bed at $3 \mathrm{pm}$. $\mathrm{PMH}$ now consistently discharges over $30 \%$ of all patients before $10 \mathrm{am}$ and $55 \%$ by 12 pm (Box $4, \mathrm{~B}$ ).

\section{Discussion}

The FHR is a powerful change-management tool that has driven the redesign of processes and clinical services throughout $\mathrm{PMH}$, improving the timeliness of care for patients presenting to the ED without any detriment to clinical care.

Critical to the success of the program has been the improvement in timely discharge of patients from

\section{Findings from the Six Sigma improvement method, Define, Measure, Analyse, Improve and Control}

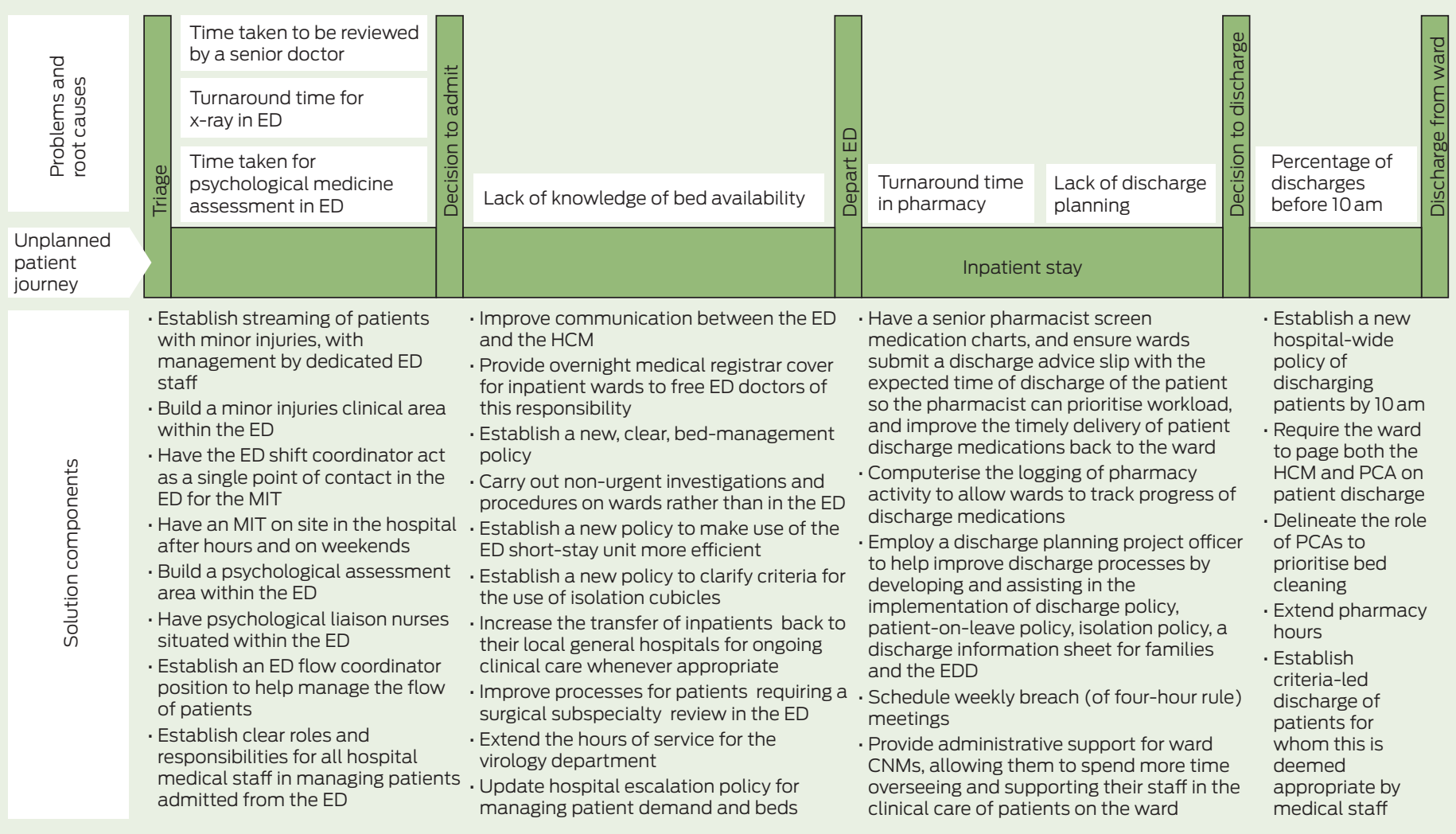


inpatient wards. During the Define phase of DMAIC, one parent noted: "it is harder to get discharged from PMH than it is to get admitted". This was a consistent complaint from families, prompting a major focus on improving discharge processes. There are now a predictable number of discharges before $10 \mathrm{am}$ and $12 \mathrm{pm}$ each day, allowing the Patient Flow Unit to plan more accurately for the predictable admissions from the ED and for elective surgery. Importantly, the improvements in early discharges were achieved without resorting to establishing a discharge lounge (an area where patients who are clinically fit for discharge wait pending arrival of their discharge medications, equipment or transport), as families made it clear that once their child was considered well enough to be discharged, they wanted to go home and not be moved to another part of the hospital.

A UK study comparing performance of hospitals close to the border between England (where waiting time targets existed) and Wales (where such targets did not), showed that patients attending English hospitals faced shorter ED waiting times and had lower mortality rates than those attending Welsh hospitals, ${ }^{23}$ consistent with the recent finding of reduced mortality rates in WA hospitals after the FHR program was introduced. ${ }^{8}$ However, there remains much debate about the pros and cons of setting targets in health, with advocates suggesting they have the potential to drive hospital-wide change and scep-

\section{Top 10 lessons learned in implementing a 4-hour-rule} program

- Ensure the focus for change is hospital-wide and involve as many people from all areas of the hospital as possible.

- Stay true to the methods and resist all temptation to "jump to solutions".

- Ensure accurate data are available in real time, and share it with all hospital staff.

- Identify and engage local champions for change.

- Ensure solutions are created and developed by staff working at grassroots level in the areas requiring change.

- Ensure there is strong governance with clear responsibility and accountability for all solutions.

- Ensure the hospital executive view the program as a priority.

- Improving discharge processes is the most effective way to reduce access block in the emergency department.

- To effect real change, targets must be a challenge to achieve.

- Ensure there are simple ways for clinical staff to raise issues or concerns in an open and non-confrontational manner.

4 Additional measures of Four Hour Rule Program performance at Princess Margaret Hospital, Perth, Western Australia

A: Length of stay in the emergency department, 2009 and 2011

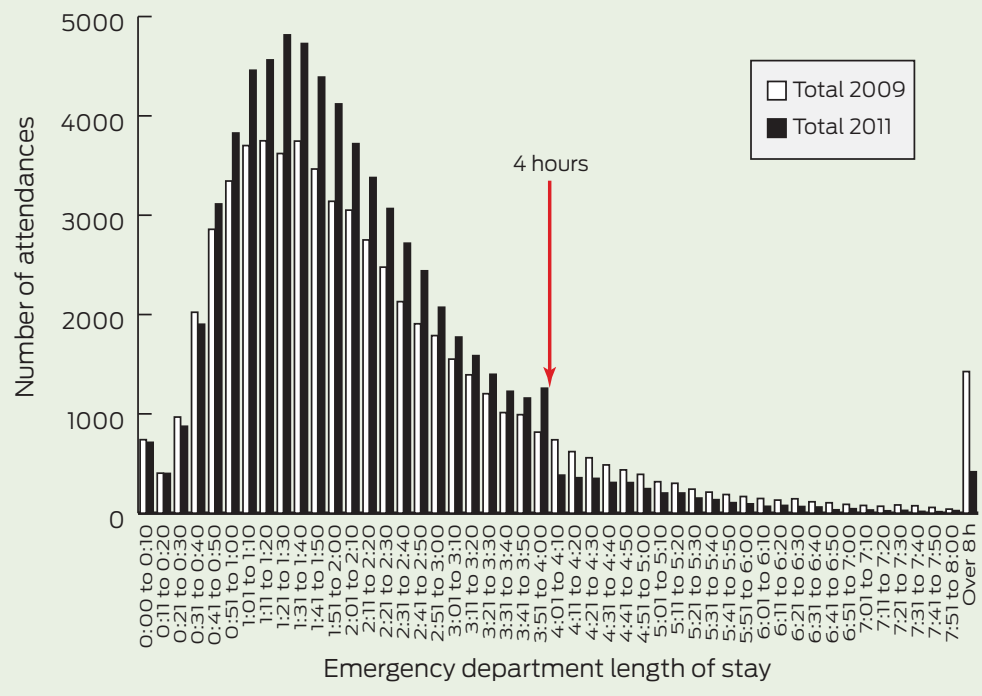

B: Percentage of patients discharged before $10 \mathrm{am}, 2009$ to 2011

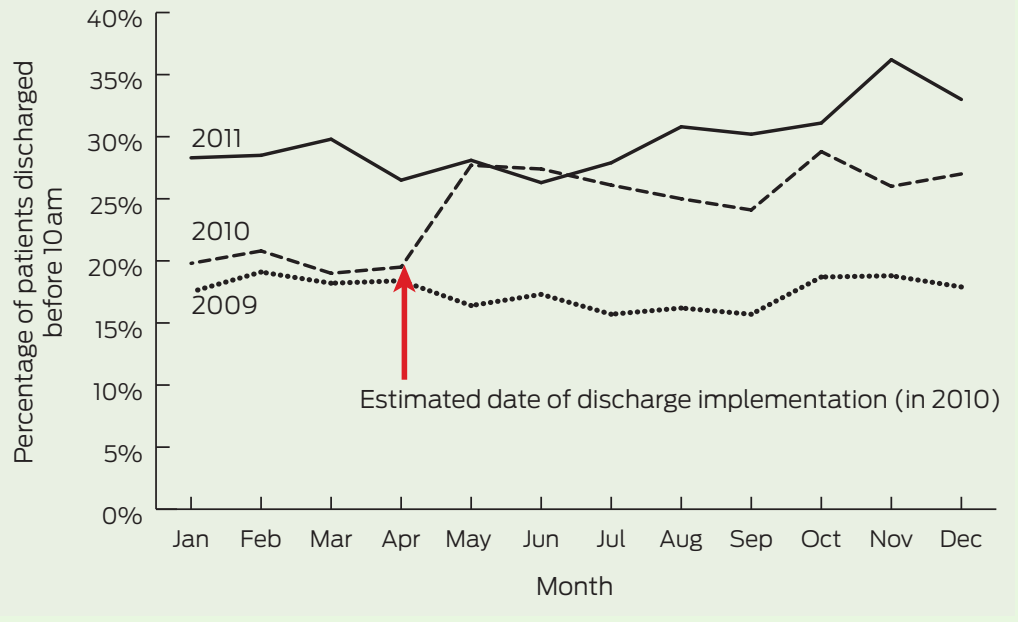

tics fearing adverse consequences, such as gaming and the neglect of areas not subject to targets. ${ }^{22,24,25}$ The strong leadership of WA's FHR program, the emphasis on monitoring performance across all areas of the hospital and the lack of financial incentives for achieving "the target", have been important factors in reducing the likelihood of adverse outcomes. In addition, while clinical staff were actively involved in the redesign process, helping to determine the direction of change, the hospital Executive made the program part of their core business and were accountable for the implementation of change. ${ }^{26}$
Good data are critical to any clinical services redesign program. The data collected at PMH was a key and powerful enabler in effecting change. It provided a clear picture of how the hospital was performing at baseline, and allowed many myths to be dispelled by using accurate, specific and clinically meaningful data that were available on a daily basis. A weekly 30-minute clinical and operational meeting has been crucial to the ongoing success of the FHR program. Representatives from all relevant hospital wards and departments attend to review weekly statistics and analyse reasons for breaches of the 4-hour 
target, allowing continual finetuning of processes.

Our study has some limitations. Our experience and results in a tertiary paediatric hospital may not be reproducible in mixed or adult tertiary hospitals where higher admission rates, patients with multiple comorbid conditions, and dependence on community services to facilitate the discharge of elderly patients, create a greater challenge. ${ }^{12}$ In addition, the quality measures that we reported were relatively limited and may not have identified all the changes (positive and negative) resulting from the FHR program accurately.

The FHR program provided a unique opportunity to redesign aspects of the patient journey, resulting in significant and sustained benefits for patients and staff. The focus of the redesign program must remain on improving the quality of care for patients, rather than on achieving "the target". The top 10 lessons we learned are summarised in Box 5.

Acknowledgements: We thank the staff at PMH who participated in the Four Hour Rule Program and the Health System Improvement Unit, Department of Health, WA.

Competing interests: No relevant disclosures.

Received 7 Jul 2012, accepted 2 Dec 2012.

1 Lowthian JA, Curtis AJ, Jolley DJ, et al. Demand at the emergency department front door: 10-year trends in presentations. Med J Aust 2012; 196: 128-132.

2 O'Connell TJ, Ben-Tovim DI, McCaughan BC, et al. Health services under siege: the case for clinical process redesign. Med J Aust 2008; 188 (6Suppl): S9-S13.

3 Australian Institute of Health and Welfare. Australian hospital statistics 2010-2011: emergency department care and elective surgery waiting times. Canberra: AlHW, 2011. (AlHW Cat.
No. HSE 115; Health Services Series No. 41.) http:// www.aihw.gov.au/publication-detail/?id= 10737420662 (accessed Jan 2012).

4 Mountain D. Introduction of a 4-hour rule in Western Australian emergency departments. Emerg Med Australas 2010; 22: 374-378.

5 Guttman A, Schull MJ, Vermeulen MJ, Stukel TA Association between waiting times and short term mortality and hospital admission after departure from emergency department; population based cohort study from Ontario, Canada. BMJ 2011; 342: d2830.

6 Sprivulis P, Da Silva J-A, Jacobs IG, et al. The association between hospital overcrowding and mortality among patients admitted via Western Australian emergency departments. Med J Aust 2006; 184: 208-212.

7 Richardson DB. Increase in patient mortality at 10 days associated with emergency department overcrowding. Med J Aust 2006; 184: 213-216.

8 Geelhoed GC, de Klerk NH. Emergency department overcrowding, mortality and the 4-hour rule in Western Australia. Med J Aust 2012; 196: 122-126.

9 Richardson DB, Mountain D. Myths versus facts in emergency department overcrowding and hospital access block. Med J Aust 2009; 190 : 369-374

10 WA Health. Emergency demand UK tour. 17-26 November 2008. Perth: Government of Western Australia Department of Health, 2008. http:// www.health.wa.gov.au/hrit/docs/publications/ WA_Health_UK_Tour_Report.pdf (accessed Dec 2012).

11 Hughes G. Four hour target for EDs: the UK experience. Emerg Med Australas 2010; 22: 368-373.

12 Stokes B. Four Hour Rule Program progress and issues review. Perth: Government of Western Australia Department of Health, 2011. http:// www.health.wa.gov.au/publications/ documents/FourHourRule_Review_Stokes.pdf (accessed Jan 2013).

13 United Kingdom Department of Health. A\&E clinical quality indicators. Data definitions. London: Department of Health, 2010. http:// www.dh.gov.uk/prod_consum_dh/groups/dh digitalassets/@dh/@en/@ps/documents/ digitalasset/dh 122892.pdf (accessed Sep 2012).

14 Australian Government Department of Health and Ageing. Expert panel - review of elective surgery and emergency access targets under the National Partnership Agreement on Improving Public Hospital Services: Supplementary Annexure. Canberra: DoHA, 2012. http:// www.yourhealth.gov.au/internet/yourhealth/ publishing nsf/Content/Expert-PanelSupplementary-Annexure/\$File/D0515_ COAG\%20Supplementary\%20Annexure SECURED.pdf (accessed Dec 2012).

15 Ben-Tovim DI, Dougherty ML, O'Connell TJ, McGrath KM. Patient journeys: the process of clinical redesign. Med J Aust 2008; 188 (6 Suppl): S14-S17.

16 Ben-Tovim DI, Bassham JE, Bennett DM, et al. Redesigning care at the Flinders Medical Centre: clinical process redesign using "lean thinking". Med J Aust 2008; 188 (6 Suppl): S27-S31.

17 O'Connell TJ, Bassham JE, Bishop RO, et al. Clinical process redesign for unplanned arrivals in hospital. Med J Aust 2008; 188 (6 Suppl): S18-S22.

18 Gygi C, DeCarlo N, Williams B. Six sigma for dummies. Hoboken, NJ: Wiley Publishing Inc, 2005.

19 Westwood N, James-Moore M, Cooke M. Going lean in the NHS. Coventry: United Kingdom National Health Service, Institute for Innovation and Improvement, 2007. http://www. birminghamcancer.nhs.uk/uploads/document file/document/4ff2d719358e9870fe000032/ going_lean_in_the_nhs.pdf (accessed Nov 2012).

20 Locker TE, Mason SM. Analysis of the distribution of time that patients spend in emergency departments. BMJ 2005; 330: 1188-1189.

21 Mason S, Nicholl J, Locker T. Targets still lead care in emergency departments. BMJ 2010; 341: c3579.

22 Mason S, Weber EJ, Coster J, et al. Time patients spend in the emergency department: England's 4-hour rule - a case of hitting the target but missing the point? Ann Emerg Med 2012; 59: 341-349.

23 Hauck K, Street A. Do targets matter? A comparison of English and Welsh national health priorities. Health Econ 2007; 16: 279-290.

24 Kelman S, Friedman JN. Performance improvement and performance dysfunction: an empirical examination of distortionary impacts of the emergency room wait-time target in the English National Health Service. J Public Adm Res Theory 2009; 19: 917-946.

25 Grubb J, Bevan G. Have targets done more harm than good in the English NHS? BMJ 2009; 338: 442-443.

26 McGrath KM, Bennett DM, Ben-Tovim DI, et al. Implementing and sustaining transformational change in health care: lessons learnt about clinical process redesign. Med J Aust 2008; 188 (6 Suppl): S32-S35. 